\title{
The Price Leading Effects among Offshore and Onshore RMB Exchange Rate Markets --- An empirical analysis based on the two stage comparison
}

\author{
Xiaoling Song ${ }^{1}, \mathrm{Ya} \mathrm{Gao}^{2}$ \\ ${ }^{1,2}$ Business School,Beijing Language and Culture University, Beijing, 100083,China
}

Keywords: RMB Onshore Market, RMB Offshore Market, Exchange Rate Fluctuations Interval, Price leading effect.

\begin{abstract}
Taking March 17, 2014 as the time spit point when the exchange rate floating range was expanded again, and using the Vector Auto Regression model, impulse response function, variance decomposition, we make a comparative analysis is on the dynamic changes in the price guide effects among the CNY, CNH and NDF market in this paper. Studies have shown that the linkage effects among the three markets have strengthened after the expansion of the exchange rate fluctuations interval. The exchange rate of CHY plays more significant leading role on $\mathrm{CNH}$ and NDF. The exchange rate price guide function of $\mathrm{CNH}$ and NDF on CHY has also increased, but the contribution is not significant. The onshore RMB market has owned the pricing power of the RMB exchange rate.
\end{abstract}

\section{Introduction}

Since July 21, 2005 when the exchange rate reform was started, China has been continuously deepening the reform in RMB exchange rate formation mechanism and the elasticity of exchange gradually increases. On April 16, 2012, the daytime RMB fluctuation range within the boarders increased from 5\% to 1\%; on March 17, 2014, the floating range in the transaction price of RMB against USD increased to 2\% again; on August 11, 2015, the middle rate in the transaction between RMB and RMB in Chinese foreign exchange market was adjusted as 6.2298, with a depreciation of $1.86 \%$. Then, a key step was taken again in the reform in RMB exchange rate formation mechanism. The series of landmark measures not only enhanced the decisive effect of market in resource allocation but also helped to facilitate China's economic and financial openness and the RMB internationalization process. Thus, it is of great realistic significance to study the price guidance effect of RMB exchange markets at home and abroad.

The price guidance effect among financial markets is very complicated. Kaen, Hachey (1983), Hartman (1984) and Swanson (1988) were the first to empirically analyze USD onshore and offshore market prices and pointed out that onshore market had the advantage of information center, so onshore market guiding offshore market is the transmission route. Park (2001), Rhee \& Lee (2005) used the exchange rate reform in South Korea in 1988 as the interval point between two phases and found through research that the exchange rate reform in South Korea in 1988 resulted in a change in the price guidance route between KRW spot exchange rate market and non-deliverable forward (NDF) market. Colavecchio and Funke (2008) built a GARCH model to explore the price guidance effect of RMB and part of other Asia national currencies among foreign exchange markets at home and abroad and concluded that the volatility spillover effect should prevail among the foreign exchange markets of national currencies studied. Besides, RMB overseas NDF market has become one of the major fluctuation centers.

In consideration of dynamic interconnections among multiple overseas RMB foreign exchange markets, Chinese scholars made researches. Dai Youyu and Yang Ying (2007) systemized the long-term casual relationship of exchange rate changes among RMB onshore market (CNY) domestic spot market, forward market and overseas NDF forward market. Located at the information center, the domestic RMB foreign exchange market has a certain guiding function on the exchange rate price. Rong Ruxiang (2008) considered the foreign exchange rate reform of 2005 as the division 
point and analyzed the relation between RMB spot exchange rate and RMB NDF one-year exchang rate by using the Granger causality test. After the exchange rate reform, regardless of the exchange rate or its change tendency, the RMB spot exchange rate and NDF exchange rate became related more closely. Yan Min and Ba Shusong (2010) investigated the price conducting mechanism among RMB foreign exchange markets at home and abroad by using the vector error correction model, multivariate GARCH model, information share model and other methods. The exchange rate reform strengthened the co-movement among foreign exchange markets at home and abroad. However, based on some restrictions on RMB market, the RMB overseas market occupies a vantage point in the information center. All such researches were single-phase researches or double-phase researches with an exchange rate reform as its division point. The objects of research were mainly the RMB onshore market exchange rate and NDF price guidance.

As Hong Kong's offshore market appeared relatively late, there are very few researches on Hong Kong CNH spot exchange rate at home and abroad. Based on the VAR model, Ding et al. (2012) analyzed and studied the dynamic interconnection between onshore and offshore market RMB exchange rates by using the impulse response function and variance decomposition. There is a certain price discovery mechanism between RMB spot exchange rate and NDF forward exchange rate price but CNH spot exchange rate doesn't show its price guidance function for the RMB exchange rates in other markets. Xia Yuanyuan and Song Xiaoling (2014)'s selection of time division point was transferred into the RMB fluctuation range expansion, used the domestic RMB fluctuation range expansion on April 16, 2012 as the time division point, respectively built the unrestricted VAR and structural VAR models, and investigated the influence of middle rate of RMB exchange rate on exchange rates at home and abroad. They found that the measure of expanding the fluctuation range of RMB exchange rate in April 2012 effectively strengthened China's right of speech for the RMB exchange rate pricing as a sovereign state.

With diversified research variables selected and research methods as well as investigations in increasingly expanding time periods, existing researches provided a powerful support for the research in this paper. On the other hand, a space of further expansion was also left. Firstly, data selected in empirical analyses were mostly data before 2013 and the time division points were mostly the exchange rate reform in 2005 or the establishment of Hong Kong RMB offshore market. Secondly, there are many researches on the interactive relationships between CNY and NDF, and CNY and $\mathrm{CNH}$ while there are only few researches on the price guidance effects among CNY, NDF and CNH. On the background of continuously promoting the marketization of RMB exchange rate formation mechanism, the research on the adjustment of floating range is of a high theoretical and application value for price guidance and connected effect among the three markets.

This paper used the event that the floating rate in the transaction price of RMB against USD expanded to 2\% on March 17, 2014 as the division point, comparatively analyzed the influence of expansion in floating range of exchange rate on the price guidance relationship among the RMB onshore market sot exchange rate (hereinafter referred to as CNY), offshore market spot exchange rate (hereinafter referred to as $\mathrm{CNH}$ ) and overseas $\mathrm{RMB}$ non-deliverable forward exchange rate (hereinafter referred to as NDF). As for the selection of the second time zone, the exchange rate reform on August 11, 2015 was included to simultaneously consider its influence. This paper, which built the VAR model and used the variance decomposition to empirically analyze the influence process and routes, offers a certain reference basis for the evaluation of the effect of exchange rate system reform.

\section{Definition of core concepts, data selection and stationarity test Definition of core concepts}

If, in the regression equation of variable $A$, the regression coefficient is of statistical significance when variable $\mathrm{B}$ lags for $\mathrm{N}$ periods (especially the first period), variable $\mathrm{B}$ has the price guidance effect on variable A; if there is the mutual price guidance effect between Party A and Party B, there is a connected effect between the two variables. 


\section{Sample selection and description}

As for the data on the selection date in this paper, March 17, 2014 was used as the division point, which divided the sample range into two phases. Phase I: from April 16, 2012 to March 14, 2014; phase II: from March 17, 2014 to March 1, 2016. The starting date of phase I was the day when the floating range of transaction price of RMB against USD in inter-bank spot foreign exchange market expanded from $5 \%$ to $1 \%$; the starting day of phase II was the day when the fluctuation range expanded from $1 \%$ to $2 \%$. After the non-corresponding daily transaction data arising from the difference in festivals at home and abroad was deleted, it is obtained through statistics that the sample data of the two phases before and after the emergence of Hong Kong RMB offshore market were 451 data respectively.

CNY selected the middle rate of USD/RMB spot exchange rate published by the State Administration of Foreign Exchange (SAFE) and CNH's data was from Wind Information. NDF selected the NDF market exchange rate of 6 months on the relatively large-scale Hong Kong offshore markets, which were developed earliest among the RMB NDF markets and the data came from Wind Information. The data required in this paper are return series of all variables with their rates of return acquired by means of logarithmic difference and are correspondingly recorded as RCNY, RCNH and RNDF.

\section{Variance stationarity test}

The corresponding $\mathrm{P}$ values of 8th-order lag of the return series of the three market are approximately 0 . The null hypothesis can be refused on the confidence level of $1 \%$ for all. Therefore, there is no unit root and all of them are stationary series.

\section{Analysis on price guidance effect}

\section{Granger causality test and analysis of its result}

The Granger causality test method was used to judge whether there is a certain influence relationship among the three markets (Table 1).

According to phse I in Table 1, within 6 orders of lag, the corresponding P values of Granger causality tests are very big and the null hypothesis cannot be refused for all of them. It indicates that there is a low relevance and no significant price guidance among the CNY market, CNH market and NDF market before the expansion of floating range of exchange rate. According to phase II in Table 1, the null hypothesis that RCNH is not the Granger cause of RCNY cannot be refused, but the null hypothesis that RNDF is not the Granger cause of RCNY can be refused when the significance level is $1 \%$. The lag between 2nd and 6th orders indicates that, for the rate of return of CNH market, the exchange rate return rates of CNY market and NDF market play a role in price guidance to some degree. After 2nd-order lag, the null hypothesis that RCNY is not the Granger cause of RNDF when the significance level is $5 \%$. With the 1st-order lag, the null hypothesis that RCNH is not the Granger cause of RNDF. Thus, it means that the return rate of $\mathrm{CNH}$ market affects the exchange rate return rate of NDF market within a short term. Meanwhile, after 2nd-order lag, RCNY and RNDF are the Granger cause of each other, indicating that there is a bi-directional guidance relationship between CNY market and NDF market. On the whole, the measure of expanding the floating range to $2 \%$ obviously strengthened links among RMB foreign exchange markets at home and abroad; in particular, the link between domestic CNH market and overseas NDF market got closer and the price guidance capability of RMB exchange rate preliminarily appeared. 
Table 1. Results of RCNY, RCNH and RNDF Granger causality test

\begin{tabular}{|c|c|c|c|c|c|c|c|}
\hline \multirow[b]{2}{*}{ Phase } & \multirow[b]{2}{*}{ Null hypothesis } & \multicolumn{6}{|c|}{$\mathrm{P}$ value } \\
\hline & & $\begin{array}{l}\text { 1st-ord } \\
\text { er lag }\end{array}$ & $\begin{array}{l}\text { 2nd-or } \\
\text { der lag }\end{array}$ & $\begin{array}{l}\text { 3rd-or } \\
\text { der lag }\end{array}$ & $\begin{array}{l}\text { 4th-or } \\
\text { der lag }\end{array}$ & $\begin{array}{l}\text { 5th-ord } \\
\text { er lag }\end{array}$ & $\begin{array}{l}\text { 6th-ord } \\
\text { er lag }\end{array}$ \\
\hline \multirow{6}{*}{$\begin{array}{l}\text { Phase } \\
\text { I }\end{array}$} & $\begin{array}{l}\text { RCNH is not the Granger cause } \\
\text { of RCNY. }\end{array}$ & 0.9666 & 0.9839 & 0.9831 & 0.8410 & 0.9673 & 0.9607 \\
\hline & $\begin{array}{l}\text { RNDF is not the Granger cause } \\
\text { of RCNY. }\end{array}$ & 0.2845 & 0.6166 & 0.5881 & 0.7456 & 0.7993 & 0.8685 \\
\hline & $\begin{array}{l}\text { RCNH is not the Granger cause } \\
\text { of RCNY. }\end{array}$ & 0.9673 & 0.7901 & 0.9044 & 0.9688 & 0.9853 & 0.9930 \\
\hline & $\begin{array}{c}\text { RNDF is not the Granger cause } \\
\text { of RCNY. }\end{array}$ & 0.1361 & 0.1834 & 0.3153 & 0.4156 & 0.5496 & 0.5704 \\
\hline & $\begin{array}{c}\text { RCNH is not the Granger cause } \\
\text { of RNDF. }\end{array}$ & 0.0955 & 0.2654 & 0.4379 & 0.3768 & 0.5021 & 0.5309 \\
\hline & $\begin{array}{l}\text { RCNH is not the Granger cause } \\
\text { of RNDF. }\end{array}$ & 0.3363 & 0.6845 & 0.8637 & 0.9353 & 0.9688 & 0.9331 \\
\hline \multirow{6}{*}{$\begin{array}{l}\text { Phase } \\
\text { II }\end{array}$} & $\begin{array}{c}\text { RCNH is not the Granger cause } \\
\text { of RCNY. }\end{array}$ & 0.4748 & 0.6779 & 0.7609 & 0.3006 & 0.4365 & 0.4417 \\
\hline & $\begin{array}{l}\text { RNDF is not the Granger cause } \\
\text { of RCNY. }\end{array}$ & 0.0000 & 0.0000 & 0.0000 & 0.0000 & 0.0000 & 0.0000 \\
\hline & $\begin{array}{c}\text { RCNH is not the Granger cause } \\
\text { of RCNY. }\end{array}$ & 0.8920 & 0.0108 & 0.0025 & 0.0209 & 0.0458 & 0.0219 \\
\hline & $\begin{array}{l}\text { RNDF is not the Granger cause } \\
\text { of RCNY. }\end{array}$ & 0.0000 & 0.0000 & 0.0000 & 0.0000 & 0.0000 & 0.0000 \\
\hline & $\begin{array}{c}\text { RCNH is not the Granger cause } \\
\text { of RNDF. }\end{array}$ & 0.5223 & 0.0010 & 0.0040 & 0.0092 & 0.0192 & 0.0106 \\
\hline & $\begin{array}{c}\text { RCNH is not the Granger cause } \\
\text { of RNDF. }\end{array}$ & 0.0105 & 0.5118 & 0.7156 & 0.9709 & 0.7799 & 0.5609 \\
\hline
\end{tabular}

\section{Building of a multivariate VAR model}

According to the selection standards for optimal lag orders such as AIC, SC, HQ and information criteria, the optimal lag periods of the two phases were determined to be the $1^{\text {st }}$ period and the $2^{\text {nd }}$ period and the multivariate VAR (1) and multivariate VAR (2) model (Table 2) were built. The reciprocals of characteristic polynomial of the AR feature of the model were all in the unit circle, so the model was stable.

As shown in Table 2, in the regression equation of RCNH and RNDF, the RCNY (-1) and RCNY (-1) regression coefficients increase significantly in phase II and their statistical significances also increase noticeably. It shows that the domestic RMB exchange rate's guidance function for Hong Kong offshore exchange rate and NDF price increases at phase II. In the regression equation of RCNY and RNDF, RCNH (-1) is not statistically significant at the two phases and RCNH doesn't show a noticeable guidance function for the prices of RCNY and RNDF. In the regression equation of RCNY and RNDH, the coefficient of RNDF (-1) changes from a negative sign into a positive one at phase II and the statistical significance increases largely. Thus, it means that RNDF's price guidance function for RCNY and RCNH, especially RCNH, increases significantly. Through the comparison of the two phases, the degree of influence of RCNH and RNDF on the price of RCNY increases significantly. 
Table 2. Result of VAR model of RCNY, RCNH and RNDF

\begin{tabular}{|c|c|c|c|c|c|c|}
\hline & \multicolumn{3}{|c|}{ Phase I } & \multicolumn{3}{|c|}{ Phase II } \\
\hline & RCNY & RCNH & RNDF & RCNY & $\mathrm{RCNH}$ & RNDF \\
\hline \multirow[t]{2}{*}{$\mathrm{C}$} & -0.005031 & -0.005203 & -0.004307 & 0.006973 & 0.010106 & 0.014367 \\
\hline & [-1.44189] & [-1.15092] & {$[-0.95081]$} & [ 1.20064] & [ 1.06283] & [ 1.02007] \\
\hline \multirow[t]{2}{*}{ RCNY(-1) } & $\begin{array}{c}0.158676^{*} \\
*\end{array}$ & 0.003277 & 0.133393 & 0.172371 & 0.248237 & 0.517452 \\
\hline & [ 2.57425] & [ 0.04103$]$ & {$[1.66687] *$} & $\begin{array}{c}{[2.85334]^{*}} \\
* *\end{array}$ & {$[2.50986]^{* *}$} & $\begin{array}{c}{[3.53188]^{* *}} \\
*\end{array}$ \\
\hline \multirow[t]{2}{*}{ RCNH(-1) } & -0.002427 & 0.188552 & 0.072407 & -0.036415 & $-0.2407 * * *$ & 0.003544 \\
\hline & {$[-0.04184]$} & {$[2.50866]^{*}$} & [ 0.96152] & [-0.87134] & [-3.51786] & [ 0.03497] \\
\hline \multirow[t]{2}{*}{ RNDF(-1) } & -0.069245 & -0.124943 & -0.028933 & $\begin{array}{c}0.244528 * \\
* *\end{array}$ & $0.501426 * * *$ & $0.128975 *$ \\
\hline & {$[-1.07031]$} & [-1.49036] & [-0.34447] & [ 7.81421] & [ 9.78718] & [ 1.69945] \\
\hline \multirow[t]{2}{*}{ RCNY(-2) } & & & & 0.076944 & $-0.185758 * *$ & $-0.249576 * *$ \\
\hline & & & & [ 1.50174$]$ & {$[-2.21443]$} & {$[-2.00849]$} \\
\hline \multirow[t]{2}{*}{ RCNH(-2) } & & & & -0.014489 & 0.075414 & 0.101332 \\
\hline & & & & [-0.38686] & [ 1.22990] & [ 1.11562] \\
\hline \multirow[t]{2}{*}{ RNDF(-2) } & & & & 0.010625 & $-0.184797 * * *$ & $-0.324056 * * *$ \\
\hline & & & & [ 0.30030$]$ & {$[-3.19018]$} & [-3.77654] \\
\hline
\end{tabular}

Note: Corresponding t statistical values are in the square brackets below the statistical values of all parameters. $* * *, * *$ and * respectively represent the significance levels of $1 \%, 5 \%$ and $10 \%$.

\section{Variance decomposition}

Phase I

As shown in Table 3, RCNY's degree of contribution to its own prediction error is stably $99.51 \%$ from the $3^{\text {rd }}$ period, indicating that there is an extremely low innovation influences from other two sequences on this sequence basically. RCNH is not only highly affected by itself but also affected by about $28 \%$ degree of contribution of RCNY. As for RNDF, both the innovations of RCNY and $\mathrm{RCNH}$ are important and their degrees of contributions to the prediction error respectively reach approximately $43 \%$ and $27 \%$. As shown in the result of variance decomposition, when the floating range is $1 \%$, the relatively independent fluctuation of return rate in CNY market is not easily affected by the changes in the return rates of the other two markets. However, the return rates of CNH market and NDF market are affected by the fluctuation in the return rate of CNY market to some extent. It means that CNY market, which has a certain advantage of domestic information center, has the price guidance function for the exchange rates in $\mathrm{CNH}$ market and NDF market.

Table 3. Result of variance decomposition of RCNY, RCNH and RNDF (phase I)

\begin{tabular}{|c|c|c|c|c|c|c|c|c|c|}
\hline \multirow{2}{*}{$\begin{array}{c}\text { Perio } \\
\text { d }\end{array}$} & \multicolumn{3}{|c|}{ RCNY } & \multicolumn{3}{|c|}{ RCNH } & \multicolumn{3}{|c|}{ RNDF } \\
\hline & RCNY & $\begin{array}{c}\mathrm{RCN} \\
\mathrm{H}\end{array}$ & $\begin{array}{c}\text { RND } \\
\text { F }\end{array}$ & RCNY & RCNH & $\begin{array}{c}\text { RND } \\
\text { F }\end{array}$ & RCNY & RCNH & RNDF \\
\hline 1 & 100 & 0 & 0 & 27.88 & 72.12 & 0 & 41.96 & 27.11 & 30.93 \\
\hline 2 & 99.51 & 0.24 & 0.25 & 27.53 & 71.99 & 0.48 & 42.71 & 26.86 & 30.42 \\
\hline 3 & 99.49 & 0.26 & 0.25 & 27.53 & 71.98 & 0.49 & 42.71 & 26.86 & 30.43 \\
\hline 4 & 99.49 & 0.26 & 0.25 & 27.53 & 71.98 & 0.49 & 42.71 & 26.86 & 30.43 \\
\hline 5 & 99.49 & 0.26 & 0.25 & 27.53 & 71.98 & 0.49 & 42.71 & 26.86 & 30.43 \\
\hline 6 & 99.49 & 0.26 & 0.25 & 27.53 & 71.98 & 0.49 & 42.71 & 26.86 & 30.43 \\
\hline 7 & 99.49 & 0.26 & 0.25 & 27.53 & 71.98 & 0.49 & 42.71 & 26.86 & 30.43 \\
\hline 8 & 99.49 & 0.26 & 0.25 & 27.53 & 71.98 & 0.49 & 42.71 & 26.86 & 30.43 \\
\hline 9 & 99.49 & 0.26 & 0.25 & 27.53 & 71.98 & 0.49 & 42.71 & 26.86 & 30.43 \\
\hline 10 & 99.49 & 0.26 & 0.25 & 27.53 & 71.98 & 0.49 & 42.71 & 26.86 & 30.43 \\
\hline
\end{tabular}




\section{Phase II}

As shown in the result of VAR (2) model, after the floating range of RMB exchange rate expanded to $2 \%$, RCNY's influence on RCNH and RNDF further expanded; meanwhile, changes in RNDF also resulted in some changes in RCNY. On the basis of this, variance decomposition was conducted for the three markets (Table 4). The result of variance decomposition got gradually stable from the $3^{\text {rd }}$ period. Compared with the period before the expansion of floating range, the influences of RCNH and RNDF on RCNY expanded, but their degrees of contribution were still low. The influence of innovation in RCNY accounts for nearly $36 \%$ of RCNH prediction error and the RNDF's degree of contribution to RCNH was also stably 15\%. For RNDF, RCNY's degree of contribution reaches 48\%, which was about a half, so RCNY alteration is most important. Meanwhile, RCNH's rate of contribution to RNDF also stays at the level of $18 \%$, which is decreased compared with rate of contribution before the expansion of floating range. In a short, after the expansion of floating range, there was a closer relationship among the three markets and higher price guidance function for each other; especially, the influence of RCNY on RCNH and RNDF was significantly deepened; meanwhile, RCNH and RNDF began to affect the alteration of RCNY. Thus, it can be seen that China's domestic foreign exchange market still keep its advantage of information center; meanwhile, the connected effect among our foreign exchange markets at home and abroad also increases continuously.

Table 4. Result of variance decomposition of RCNY, RCNH and RNDF (phase II)

\begin{tabular}{|c|c|c|c|c|c|c|c|c|c|}
\hline \multirow{2}{*}{$\begin{array}{c}\text { Peri } \\
\text { od }\end{array}$} & \multicolumn{3}{|c|}{ RCNY } & \multicolumn{3}{|c|}{ RCNH } & \multicolumn{3}{|c|}{ RNDF } \\
\hline & RCNY & $\begin{array}{c}\text { RCN } \\
\mathrm{H}\end{array}$ & $\begin{array}{c}\text { RND } \\
\text { F }\end{array}$ & RCNY & $\mathrm{RCNH}$ & RNDF & RCNY & RCNH & RNDF \\
\hline 1 & 100 & 0 & 0 & 26.05 & 73.95 & 0 & 43.44 & 20.02 & 36.54 \\
\hline 2 & 88.04 & 3.14 & 8.81 & 35.61 & 50.83 & 13.57 & 47.68 & 18.53 & 33.79 \\
\hline 3 & 88.12 & 3.11 & 8.76 & 35.25 & 49.76 & 14.99 & 47.90 & 18.15 & 33.96 \\
\hline 4 & 88.11 & 3.11 & 8.78 & 35.86 & 49.17 & 14.97 & 48.03 & 18.12 & 33.85 \\
\hline 5 & 88.10 & 3.12 & 8.78 & 35.87 & 49.16 & 14.97 & 48.03 & 18.12 & 33.85 \\
\hline 6 & 88.10 & 3.12 & 8.78 & 35.87 & 49.15 & 14.97 & 48.03 & 18.12 & 33.85 \\
\hline 7 & 88.10 & 3.12 & 8.78 & 35.88 & 49.15 & 14.97 & 48.03 & 18.12 & 33.85 \\
\hline 8 & 88.10 & 3.12 & 8.78 & 35.88 & 49.15 & 14.97 & 48.03 & 18.12 & 33.85 \\
\hline 9 & 88.10 & 3.12 & 8.78 & 35.88 & 49.15 & 14.97 & 48.03 & 18.12 & 33.85 \\
\hline 10 & 88.10 & 3.12 & 8.78 & 35.88 & 49.15 & 14.97 & 48.03 & 18.12 & 33.85 \\
\hline
\end{tabular}

\section{Conclusion and Enlightenment}

On the big background that China energetically propelled the course of RMB internationalization, this paper studied the price guidance mechanism among CNY, CNH and NDF.

Before the floating range of exchange rate expanded to $2 \%$, there was a weak link among the three markets. In particular, compared with the CNH market and NDF market, the fluctuation of CNY market exchange rate was strongly independent and was not easily influenced by any change in the exchange rates of the other two markets. After expansion of floating range, CNY spot exchange rate's influence on $\mathrm{CNH}$ spot exchange rate and NDF forward exchange rate was further depended. Besides, RNDF's price guidance function for RCNY and RCNH, especially RCNH, significantly increased. It is maybe because that they both are located at Hong Hong financial center and share the same information. Through the comparison of the two phases, RCNH and RND's degrees of influence on the price of RCNY increased significantly.

The expansion of floating range of RMB exchange rate enhanced the connected effect and price guidance effect among foreign exchange markets at home and abroad, also continuously increased the influence of RMB on the offshore market spot exchange rate. Therefore, it is required to fully take 
advantage of this tendency, try to establish a floating range expansion mechanism, properly reduce government intervention in good time and ceaselessly enhance the degree of RMB marketization in the process of RMB exchange rate formation mechanism reform. However, during the propulsion of exchange rate reform, it is also required to control the adjustment frequency of floating range, avoid excessively large fluctuations in RMB exchange rate, guarantee the status of pricing center of RMB offshore market and promote the enhancement of international status of RMB.

\section{Acknowledgement}

National Sci-Tech Support Plan of the "12 ${ }^{\text {th }}$ Five-Year Plan", "Research, Development and Demonstration of Key Financial ServiceTechnologies and System in Villages and Towns" (Project No.: 2014BAL07B03); department-level scientific research project of Beijing Language and Culture University (supported by "the Fundamental Research Funds for the Central Universities) (project No.: 15YJ0408)

\section{References}

[1] Colavecchio R,and Funke M. Volatility Transmissions between Renminbi and Asia-Pacific On-shore and Offshore US Dollar Futures, China Economic Review, 2008, 19(4):635-648.

[2] Ding David, Yiuman Tse,and Williams. The Price Discovery Puzzle in Offshore Yuan Trading: Different Contributions for Different Contract, Journal of Futures Markets online published. http://onlinelibrary.wiley.com/doi/10.1002/fut.21575/full,2012-07-24.

[3] Huang-Gay Fung, Wai K.L., Jiang Zhu. Nondeliverable Forward Market for Chinese RMB: A First Look, China Economic Review, 2004, 15(3),348-352.

[4] Frenkel M. et al. The effects of Japanese foreign exchange market interventions on the Yen/US dollar exchange rate volatility, International Review of Economics and Finance. 2005, 14(1):27-39.

[5] Park, J. Information Flows between Non-deliverable Forward (NDF) and Spot Markets: Evidence from Korean Currency, Pacific-Basin Finance Journal, 2001(9):363-377.

[6] Rhee, G.J., and E. M. Lee. Foreign Exchange Intervention and Foreign Exchange Market Development in Korea , 2005, BIS Paper, No.24.

[7] Dai Youyu and Yang Ying. Empirical research on the relationship among RMB overseas NDF exchange rate, domestic forward exchange rate and spot exchange rate, Research on International Finance, 2007, (10): 72-80.

[8] Rong Ruxiang. Research on the problem of RMB exchange rate pricing power: empirical inspection based on NDF and spot exchange rate, Shanghai Finance, 2008, (12): 69-73 .

[9] Xia Yuanyuan and Song Xiaoling. Research on RMB exchange rate pricing power of domestic inter-bank foreign exchange market, Financial Forum, 2014, (3): 45-52.

[10] Yan Min and Ba Shusong. Linkage among RMB forward markets at home and abroad and ownership of pricing power: enlightenment of empirical inspection and policy, Economic Science, 2010, (1): 72-84. 